\title{
IIIIII Primary Care Providers' Judgments of Opioid Analgesic Misuse in a Community-Based Cohort of HIV-Infected Indigent Adults
}

\author{
Maya Vijayaraghavan, MD ${ }^{1,3}$, Joanne Penko, MS, MPH ${ }^{1,3}$, David Guzman, $\mathrm{MSPH}^{1,3}$, \\ Christine Miaskowski, RN, PhD, FAAN ${ }^{2,3}$, and Margot B. Kushel, MD ${ }^{1,3}$
}

'Division of General Internal Medicine/San Francisco General Hospital, University of California, San Francisco, San Francisco, CA, USA; ${ }^{2}$ Department of Physiological Nursing, University of California, San Francisco, San Francisco, CA, USA; ${ }^{3}$ University of California, San Francisco, San Francisco, CA, USA.

BACKGROUND: Primary care providers (PCPs) must balance treatment of chronic non-cancer pain with opioid analgesics with concerns about opioid misuse.

OBJECTIVE: We co-enrolled community-based indigent adults and their PCPs to determine PCPs' accuracy of estimating opioid analgesic misuse and illicit substance use.

DESIGN: Patient-provider dyad study.

PARTICIPANTS: HIV-infected, community-based indigent adults ('patients') and their PCPs.

MAIN MEASURES: Using structured interviews, we queried patients on use and misuse of opioid analgesics and illicit substances. PCPs completed patient- and provider-specific questionnaires. We calculated the sensitivity, specificity, and measures of agreement between PCPs' judgments and patients' reports of opioid misuse and illicit substance use. We examined factors associated with PCPs' thinking that their patients had misused opioid analgesics and determined factors associated with patients' misuse.

KEY RESULTS: We had 105 patient-provider dyads. Of the patients, 21 had misused opioids and 45 had used illicit substances in the past year. The sensitivity of PCPs' judgments of opioid analgesic misuse was $61.9 \%$ and specificity, 53.6\% (Kappa score 0.09, p=0.10). The sensitivity of PCPs' judgments of illicit substance use was $71.1 \%$ and specificity, 66.7\% (Kappa score 0.37 , $\mathrm{p}<0.001)$. PCPs were more likely to think that younger patients (Adjusted odds ratio (AOR) 0.89, 95\% CI 0.840.97), African American patients (AOR 2.53, 95\% CI 1.05-6.07) and those who had used illicit substances in the past year (AOR 3.33, 95\% CI 1.35-8.20) had misused opioids. Younger (AOR 0.94, 95\% CI 0.861.02) and African American (AOR 0.71, 95\% CI 0.251.97) patients were not more likely to report misuse, whereas persons who had used illicit substances were (AOR 3.01, 95\% CI 1.04-8.76).

CONCLUSION: PCPs' impressions of misuse were discordant with patients' self-reports of opioid analgesic misuse. PCPs incorrectly used age and race as predictors of misuse in this high-risk cohort.

Received August 3, 2010

Revised October 6, 2010

Accepted October 11, 2010

Published online November 9, 2010
KEY WORDS: opioid misuse; substance use; PCP judgments; chronic pain.

J Gen Intern Med 26(4):412-8

DOI: $10.1007 / \mathrm{s} 11606-010-1555-\mathrm{y}$

(C) The Author(s) 2010. This article is published with open access at Springerlink.com

\section{INTRODUCTION}

Chronic non-cancer pain (CNCP) is common among primary care patients. There has been a rise in prescription opioid analgesic use for the treatment of $\mathrm{CNCP}^{1,2}$, and a rise in opioid analgesic misuse, with a prevalence of $9 \%$ to $41 \%$ in patients treated with opioid analgesics for $\mathrm{CNCP}^{3-6}$. Patients with HIV/AIDS have a high prevalence of chronic pain (prevalence 40\%-60\%), mental health, and substance use disorders ${ }^{11-14}$. On the one hand, mental health and substance use disorders are associated with opioid analgesic misuse ${ }^{7-9}$, and on the other hand, they are also risk factors for under treatment of pain in HIV-infected patients $^{10,11}$. Clinicians must rely on existing tools and their judgment of patients' likelihood of misuse before continuing to prescribe opioid analgesics. Studies have shown that clinicians judge non-white patients to have a higher risk for prescription opioid misuse when compared to white patients ${ }^{15,16}$. However, existing data do not support these beliefs ${ }^{7,8}$.

There are several risk stratification tools that rely on patients' self-reports of misuse ${ }^{17-22}$; none have adequate sensitivity and specificity to guide treatment decisions ${ }^{23}$. Clinicians can use urine toxicology screens, pill and patch counts to measure adherence and monitor for use of non-prescribed opioid analgesics or illicit substances ${ }^{24}$. A recent systematic review found insufficient evidence for routine urine toxicology testing because of the difficulty interpreting negative tests, which could indicate diversion, inadequate treatment of pain, or inadequate test sensitivity ${ }^{24-26}$. Another element of risk assessment is clinicians' impressions. Few studies have examined clinicians' impressions of misuse ${ }^{27}$, and none have directly compared clinicians' opinions of misuse to patients' self-reports.

We conducted a patient-provider dyad study, co-enrolling members of a representative community-based cohort of indigent adults with HIV-infection and their primary care providers (PCPs) to determine the concordance and discordance of PCPs' judgments about prescription opioid misuse and illicit substance use compared to patients' self-reports. We hypothesized 
that PCPs' estimates of misuse would have a low concordance with patients' self-reports. We hypothesized that PCPs would overestimate risk in African American patients, while underestimating risk in white patients.

\section{METHODS}

\section{Study Patients and Sampling}

We enrolled patient participants ("patients") into the dyad study from a two-year longitudinal study of pain, use and misuse of opioid analgesics in a community-based sample of indigent adults (Pain Study). We recruited members of the Pain Study from the pre-existing Research on Access to Care in the Homeless (REACH) study, a longitudinal study of HIV-infected adults in San Francisco who were systematically sampled from homeless shelters, free meal programs, and low-rent singleroom occupancy hotels ${ }^{28}$. We offered participation, regardless of pain status, to all active REACH members between September 2007 and June $2008(n=337) ; 296$ (87.8\%) completed enrollment and baseline activities.

One year into the Pain Study, we began enrolling primary care providers (PCPs) identified by Pain Study patients. We recruited the PCP that each study patient identified, if the patient gave informed consent and the identified PCP met our definition (physician, Nurse Practitioner (NP), or Physician Assistant (PA) providing longitudinal, comprehensive care).

All study protocols were reviewed and approved by the University of California, San Francisco (UCSF), Institutional Review Board; we obtained a Certificate of Confidentiality from the National Institute on Drug Abuse. We told both patients and PCPs that the information they provided would be kept anonymous and not shared with the other party.

\section{Study Procedures}

We conducted data collection from the patients at the UCSF Clinical and Translational Research Institute's Tenderloin Clinical Research Center (TCRC), a community-based university-research site. Trained research assistants administered the Pain Study and REACH study questionnaires every three months. At the baseline Pain Study interview, a trained interviewer administered the Diagnostic Interview ScheduleIV (DIS-IV) substance modules (cocaine, methamphetamine, and heroin) ${ }^{29}$. At each REACH study quarterly visit, trained interviewers obtained information on current illicit substance use. At each Pain Study quarterly visit, patients answered questions about prescription opioid analgesic misuse using Audio Computer Assisted Self-Interview (ACASI) technology ${ }^{30}$.

We recruited and collected data from PCPs by mail, using a modified version of Dillman's Tailored Design Method ${ }^{31}$. PCPs completed a short, provider-specific questionnaire and a separate patient-specific questionnaire for each of their dyadstudy patients. PCPs were encouraged, but not required, to access their patients' medical records while completing the patient-specific questionnaires.

We reimbursed patients $\$ 20.00$ for the baseline Pain Study interview, \$5.00 for each Pain Study quarterly interview, and $\$ 20.00$ for each $\mathrm{REACH}$ study quarterly interview. PCPs received a $\$ 10.00$ gift certificate for each completed questionnaire.

\section{Variable Definitions}

Patients. At the baseline Pain Study and REACH study visits, patients self-reported information on demographics (age and sex), race/ethnicity (white, African American, Hispanic, or mixed/other), residential stability, jail and prison stays, mean monthly income, insurance status (Medicaid/ Medicare, AIDS Drug Assistance Program (ADAP), or uninsured), and lifetime tobacco history (smoked at least 100 cigarettes in lifetime). We administered the Beck Depression Inventory - II (BDI) and classified depression as moderate to severe (BDI score $>19$ ) or none or mild (BDI score $\leq 19)^{32,33}$. We administered the Brief Pain Inventory $(\mathrm{BPI})^{34}$, and using patients' self-reports of average intensity of pain in the past 7 days and cut-point analysis, we classified pain as mild (0-3), moderate (4-5), or severe (6-10) ${ }^{35}$.

We created an inventory of opioid analgesic misuse behaviors that have been previously described in the literature ${ }^{14,36-38}$. We defined opioid analgesic misuse as getting high, altering the route, selling, stealing, forging prescriptions, trading street drugs for opioids, and exchanging opioids for sex in the past 90 days. We used patients' ACASI self-reports of misuse from four quarterly interviews to create a dichotomous variable that measured past-year misuse. We created a variable that combined responses for getting high, altering the route or selling prescription opioids ("one or more misuse behaviors") to mirror what we had asked PCPs.

We obtained self-reports of illicit substance use (cocaine, methamphetamine, and heroin) in the past 90 days from the REACH quarterly interviews, and created a dichotomous variable of any illicit substance use in the past year based on four quarterly interviews. We diagnosed lifetime substance abuse or dependence for cocaine, methamphetamine, and heroin using the DIS-IV instrument ${ }^{29}$. We used the DIS-IV question, "Which one of these have you used more than five times when they were not prescribed for you, or for longer than prescribed, to feel more active or alert, or to feel good or high?" to define lifetime substance use of cocaine, methamphetamine, and heroin.

\section{Primary Care Providers}

In the provider-specific questionnaires, PCPs answered questions on demographics (age and sex), race/ethnicity (white, African American, Hispanic, or Asian/Pacific Islander), clinical training (physician, NP or PA), specialty for physicians (internists, family practice or other), subspecialty for internists (Infectious disease (ID) or HIV), and years in clinical training ( 4 to 9 years, 10 to 19 years, $\geq 20$ years).

In the patient-specific questionnaire, PCPs reported whether they had prescribed that patient an opioid analgesic, and whether they had ordered urine or blood toxicology screens. Using a 5-point Likert scale, PCPs reported whether their study patient had misused opioid analgesics by getting high, altering the route, or selling these medications. We classified responses as affirmative (maybe, probably or definitely) versus negative (probably not or definitely not). We asked PCPs' to 
estimate (yes versus no or don't know) whether the dyad-study patients they were responding for had used individual illicit substances (cocaine, methamphetamine, and heroin). We created a variable that measured PCPs' composite affirmative responses of any illicit substance use in the past year for each patient under their care.

\section{Statistical Analysis}

We compared dyad-study patients' self-reports of opioid analgesic misuse or illicit substance use with their corresponding PCPs' assessments. We matched the date that the PCP completed the patient-specific questionnaire to the closestoccurring quarterly interview completed by the patient, and included three prior quarterly interviews to create a one-year assessment time period.

We restricted our analysis to patients who were prescribed an opioid analgesic in the past year based on PCPs' reports. We calculated the sensitivity and specificity of PCPs' opinions of opioid analgesic misuse and illicit substance use compared to patients' self-reports, and used the Kappa statistic to measure concordance between PCPs' opinions and patients' self-reports.

We used logistic regression to examine patient factors that were associated with PCPs' thinking that their patients had misused prescription opioid analgesics in the past year. We used patients' age, sex, race (African American versus non-African American) and history of illicit substance use in the past year as independent variables as these have been shown to predict opioid misuse or to be associated with PCPs' perception of misuse in prior studies. We then determined if any of these factors were independent predictors of patients' self-reports of past-year misuse. All analyses were conducted using Stata software, version 11.

\section{RESULTS}

\section{Sample Characteristics}

Of the 296 patients initially enrolled in the parent Pain Study, 272 (91.9\%) were active in follow-up during data collection for the dyad study, of whom 269 (98.9\%) provided written consent allowing us to contact their PCP (Fig. 1). Of these, 240 (89.3\%) named a provider who fit the definition of PCP and had confirmable contact information. The 240 patients identified 90 unique PCPs from 23 clinical settings. We obtained responses from 61 PCPs (67.8\%) who responded on 169 patients (70.4\%). Of these 169 patients, 105 (62.1\%) were prescribed an opioid analgesic by PCPs in the past year. Of the 105 patients, $80.8 \%$ $(n=84)$ were prescribed an opioid analgesic for treatment of chronic pain with the intention of taking the medication regularly for more than one month. PCPs reported ordering urine or blood toxicology screens on $27.6 \%$ of patients in the past year. We reported results on 105 patient-provider dyads.

The mean age of the patients who were prescribed an opioid analgesic in the past year was 50 (Table 1). The majority of patients were male (61.9\%), and $48.6 \%$ were

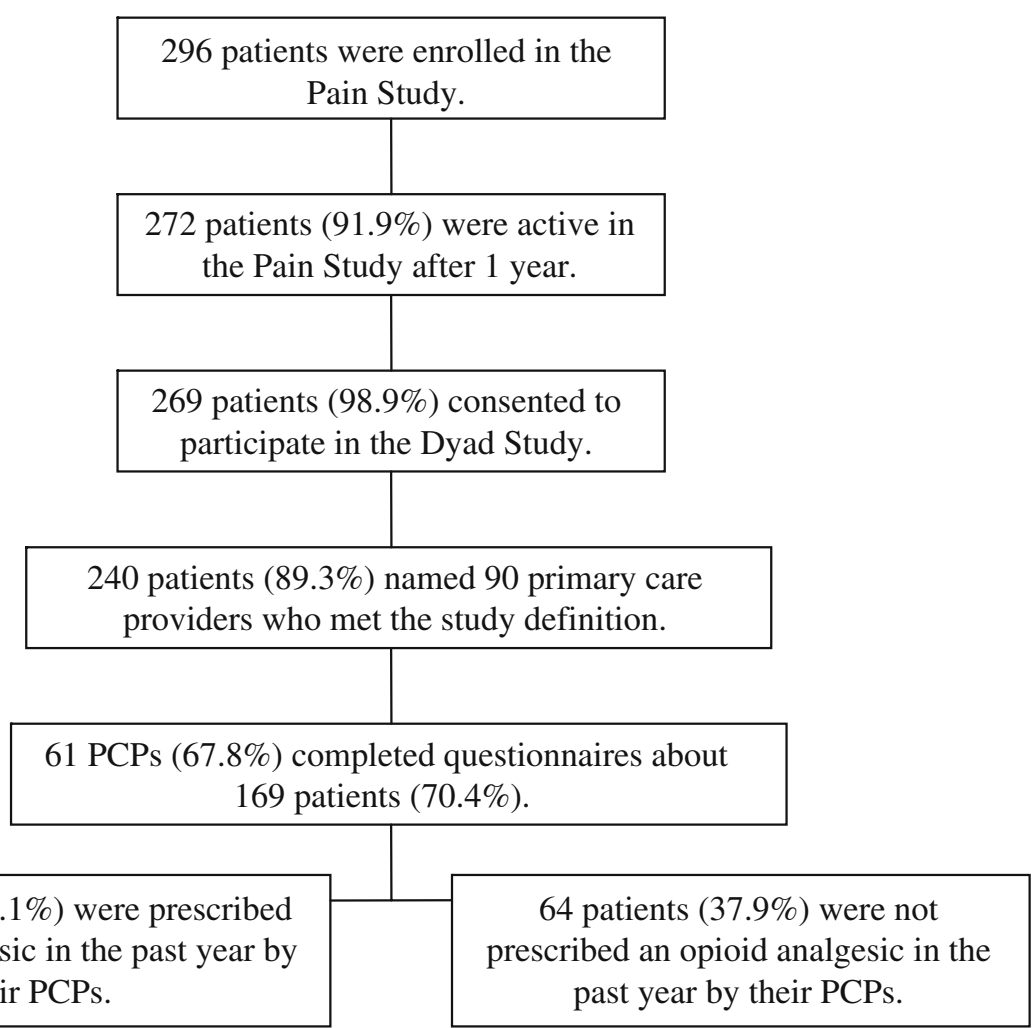

Figure 1. Patient flow. 
Table 1. Patient Characteristics by Prescription Opioid Analgesic Use in the Past Year

\begin{tabular}{|c|c|c|c|c|}
\hline \multirow[t]{3}{*}{ Characteristic } & \multirow{2}{*}{$\begin{array}{l}\text { Total } \\
\mathrm{N}=169\end{array}$} & \multirow{2}{*}{$\begin{array}{l}\text { Prescribed } \\
\text { Opioid } \\
\mathrm{N}=105\end{array}$} & \multirow{2}{*}{$\begin{array}{l}\text { Not Prescribed } \\
\text { Opioid } \\
\mathrm{N}=64\end{array}$} & \multirow{2}{*}{ P-Value } \\
\hline & & & & \\
\hline & $\mathrm{N}(\%)$ & $\mathrm{N}(\%)$ & $\mathrm{N}(\%)$ & \\
\hline Age, Mean (SD) & $50.4(7.26)$ & 50.5 (6.95) & $50.2(7.80)$ & 0.79 \\
\hline Female & $59(34.9)$ & $40(38.1)$ & $19(29.7)$ & 0.27 \\
\hline \multicolumn{5}{|l|}{ Race/Ethnicity } \\
\hline White & 60 (35.5) & $39(37.1)$ & $21(32.8)$ & \multirow[t]{4}{*}{0.49} \\
\hline African American & $79(46.8)$ & $51(48.6)$ & $28(43.8)$ & \\
\hline Hispanic & $17(10.1)$ & $8(7.6)$ & $9(14.1)$ & \\
\hline Other/Mixed & $13(7.7)$ & $7(6.7)$ & $6(9.4)$ & \\
\hline \multicolumn{5}{|l|}{ Education } \\
\hline Less Than High School & 149 (29.2) & $32(30.8)$ & $17(26.7)$ & \multirow[t]{4}{*}{0.82} \\
\hline High School & 75 (44.6) & $46(44.2)$ & $29(45.3)$ & \\
\hline More Than & $44(26.2)$ & $26(25.0)$ & $18(28.1)$ & \\
\hline High School & & & & \\
\hline \multicolumn{5}{|l|}{ Residential History } \\
\hline $\begin{array}{l}\text { Lifetime History } \\
\text { of Homelessness }\end{array}$ & $136(81.9)$ & 87 (84.5) & $49(77.8)$ & 0.28 \\
\hline $\begin{array}{l}\text { Lifetime History of } \\
\text { Being Jailed }\end{array}$ & $149(88.2)$ & $96(91.4)$ & $53(82.8)$ & 0.09 \\
\hline $\begin{array}{l}\text { Lifetime History of } \\
\text { Being in Prison }\end{array}$ & $25(15.7)$ & $17(17.4)$ & $8(13.1)$ & 0.48 \\
\hline $\begin{array}{l}\text { Mean Monthly } \\
\text { Income }\end{array}$ & $\$ 919$ & $\$ 930$ & $\$ 900$ & 0.59 \\
\hline \multicolumn{5}{|l|}{ Insurance } \\
\hline Medicaid/Medicare & $89(52.7)$ & $57(54.3)$ & $32(50.0)$ & 0.58 \\
\hline $\begin{array}{l}\text { AIDS Drug } \\
\text { Assistance Program }\end{array}$ & $69(42.1)$ & $40(39.6)$ & $29(46.0)$ & 0.42 \\
\hline Uninsured & $10(5.9)$ & $5(4.8)$ & $5(7.8)$ & 0.42 \\
\hline \multicolumn{5}{|l|}{ Depression } \\
\hline $\begin{array}{l}\text { Moderate to Severe } \\
\text { (BDI Score >19) }\end{array}$ & 47 (26.6) & $33(31.4)$ & $12(18.8)$ & 0.07 \\
\hline \multicolumn{5}{|c|}{ Average Intensity of Chronic Pain, Past 7 Days } \\
\hline Mild & $44(26.0)$ & $20(19.1)$ & $24(37.5)$ & \multirow[t]{3}{*}{0.004} \\
\hline Moderate & $43(25.4)$ & $24(22.9)$ & 19 (29.7) & \\
\hline Severe & $82(48.5)$ & $61(58.1)$ & $21(32.8)$ & \\
\hline \multicolumn{5}{|l|}{ Smoking } \\
\hline $\begin{array}{l}\text { Lifetime } \\
\text { Smoking History }\end{array}$ & $142(84.0)$ & $89(84.8)$ & $53(82.8)$ & 0.74 \\
\hline \multicolumn{5}{|c|}{ Lifetime History of Substance Abuse or Dependence* } \\
\hline Cocaine & $97(59.2)$ & $59(58.4)$ & $38(60.3)$ & 0.81 \\
\hline Methamphetamine & 67 (40.6) & 38 (37.3) & $29(46.0)$ & 0.27 \\
\hline Heroin & 49 (29.9) & $29(28.7)$ & $20(31.8)$ & 0.68 \\
\hline \multicolumn{5}{|c|}{ Lifetime History of Substance Use ${ }^{\dagger}$} \\
\hline Cocaine & $128(77.1)$ & $81(78.6)$ & 47 (74.6) & 0.55 \\
\hline Methamphetamine & $95(57.2)$ & $56(54.4)$ & 39 (61.9) & 0.34 \\
\hline Heroin & $75(45.2)$ & 49 (47.6) & 26 (41.3) & 0.43 \\
\hline
\end{tabular}

* DIS-IV diagnosis of lifetime cocaine, methamphetamine and heroin abuse or dependence

${ }^{\dagger}$ DIS-IV diagnosis of lifetime cocaine, methamphetamine and heroin use

African American. Almost half (44.2\%) had completed high school. Patients who were prescribed an opioid analgesic in the past year did not differ significantly from those who were not, except for reports of severe pain in the past week (58.1\% vs. $32.8 \%$; p $<0.004)$.

The mean age of PCPs was 47 (Table 2). Among the PCPs, $45.9 \%$ were female, and $80.3 \%$ were white. The majority (81.9\%) of PCPs were physicians, $16.4 \%$ were NPs, and $1.6 \%$ were PAs. Among physicians, $80.0 \%$ were internists. Of the internists, $37.5 \%(n=15)$ were ID subspecialists and $17.5 \%$ $(\mathrm{n}=7)$ were HIV specialists.
Table 2. Characteristics of Primary Care Providers $(\mathrm{N}=61)$

\begin{tabular}{ll}
\hline \hline Characteristic & N (\%) \\
\hline Age, Mean (SD) & $46.7(8.3)$ \\
Female & $28(45.9)$ \\
Race/Ethnicity & $49(80.3)$ \\
White & $1(1.6)$ \\
African American & $5(8.2)$ \\
Hispanic & $6(9.8)$ \\
Asian or Pacific Islander & \\
Clinical Training & $50(81.9)$ \\
Physician & $10(16.3)$ \\
Nurse Practitioner & $1(1.6)$ \\
Physician Assistant & \\
Specialty for Physicians & $40(80.0)$ \\
Internal Medicine & $7(14.0)$ \\
Family Practice & $3(5.0)$ \\
Other & \\
Subspecialty for Physicians & $15(37.5)$ \\
Infectious Disease & $7(17.5)$ \\
HIV & $2(5.0)$ \\
Other & \\
Years in Clinical Practice & $11(18.0)$ \\
4-9 years & $31(50.8)$ \\
10-19 years & $19(31.2)$ \\
$\geq 20$ years &
\end{tabular}

\section{Prevalence of Opioid Analgesic Misuse and PCPs' Judgments of Misuse}

Among the 105 patients who were prescribed an opioid analgesic, 21 (20.0\%) self-reported getting high, altering the route or selling prescription opioids in the past year (Table 3). Of these 21 patients, 8 were African Americans (38.1\%), 11 were whites $(52.4 \%)$, and 2 were Hispanic/other race $(9.5 \%)$ $(\mathrm{p}=0.45)$.

PCPs estimated that half $(49.5 \%)$ of the patients got high, altered the route, or sold opioid analgesics in the past year. The sensitivity of PCPs' opinions of their patients misusing opioid analgesics in the past year was $61.9 \%$ (95\% CI 38.4\% - 81.9\%) and the specificity was $53.6 \%$ (95\% CI $42.4 \%$ - 64.5\%) (Table 4). PCPs did not identify $38.1 \%(8 / 21)$ of patients who reported misusing opioid analgesics, and mis-identified 46.4\% (39/84) who did not report doing so. There was no concordance between PCPs' opinions and patients' self-reports of misuse behaviors in the past year (Kappa score 0.09, $\mathrm{p}=0.10$ ).

Table 3. Self-Reported Prevalence of Prescription Opioid Analgesic Misuse in the Past Year $(\mathrm{N}=105)$

\begin{tabular}{ll}
\hline \hline & N (\%) \\
\hline Used opioid analgesic to get high & $13(12.4)$ \\
Sold opioid analgesic & $10(9.5)$ \\
Snorted, crushed, injected or smoked opioid analgesic & $5(4.8)$ \\
Licked or dissolved opioid analgesic & $4(3.8)$ \\
Altered the route of opioid analgesic & $8(7.6)$ \\
Exchanged opioid analgesic for sex or drugs & $5(4.8)$ \\
Stole opioid analgesic from an individual & $5(4.8)$ \\
Stole opioid analgesic from a pharmacy, hospital or clinic & $2(1.9)$ \\
Forged a prescription for opioid analgesic & $4(3.8)$ \\
Traded street drugs to get opioid analgesic & $5(4.8)$ \\
Getting high or altering the route or selling opioid analgesic & $21(20.0)$
\end{tabular}


Table 4. Primary Care Providers' Judgment of Opioid Analgesic Misuse and Illicit Substance Use in the Past Year Compared to Patients' SelfReports $(\mathrm{N}=105)$

\begin{tabular}{|c|c|c|c|c|}
\hline & Sensitivity \%(TP/TP+FN) * & Specificity \%(TN/TN+FP) * & Agreement \% & Kappa Coefficient \\
\hline \multicolumn{5}{|l|}{ Opioid Analgesic Misuse } \\
\hline Getting high on opioids & $38.5(5 / 13)$ & $67.4(62 / 92)$ & 63.8 & 0.03 \\
\hline Altering the route of opioids & $37.5(3 / 8)$ & $92.8(90 / 97)$ & 88.6 & $0.27^{\dagger}$ \\
\hline Selling opioids & $50.0(5 / 10)$ & $56.8(54 / 95)$ & 56.2 & 0.03 \\
\hline One or More Misuse Behaviors & $61.9(13 / 21)$ & $53.6(45 / 84)$ & 55.2 & 0.09 \\
\hline \multicolumn{5}{|l|}{ Illicit Substance Use } \\
\hline Cocaine & $74.3(26 / 35)$ & $71.2(47 / 66)$ & 72.3 & $0.43^{\ddagger}$ \\
\hline Methamphetamine & $56.5(13 / 23)$ & $87.3(69 / 79)$ & 80.4 & $0.44^{\ddagger}$ \\
\hline Heroin & $27.3(3 / 11)$ & $93.6(87 / 93)$ & 86.5 & $0.23^{\dagger}$ \\
\hline Used One or More Illicit Substances & $71.1(32 / 45)$ & $66.7(40 / 60)$ & 68.6 & $0.37^{\ddagger}$ \\
\hline
\end{tabular}

${ }^{*}$ Abbreviations: TP, True Positive; TN, True Negative; FP, False Positive; FN, False Negative.

${ }^{\dagger} p<0.01$

${ }^{\ddagger} p<0.001$

\section{Prevalence of Illicit Substance Use and PCPs' Judgments of Substance Use}

More than a third of the patients ( $n=45,42.9 \%)$ self-reported using one or more illicit substances in the past year: $34.3 \%$ $(n=36)$ self-reported using cocaine, $24.8 \%(n=26)$ methamphetamine, and 10.5\% ( $=11)$ heroin (Table 4). African Americans $(37.8 \%)$ were as likely as whites $(44.4 \%)$ to self-report using one or more illicit substances in the past year $(\mathrm{p}=0.14)$.

PCPs estimated that $49.5 \%$ had used one or more illicit substances in the past year. The sensitivity of PCPs' opinions of patients using one or more substances in the past year was $71.1 \%(95 \%$ CI $55.7 \%-83.6 \%)$ and the specificity was $66.7 \%$ (95\% CI 53.3\% - 78.3\%) (Table 4). PCPs overestimated illicit substance use in 33.3\% (20/60) and underestimated in $28.9 \%$ $(13 / 45)$ of patients. PCPs' impressions were concordant with patients' self-reports (Kappa score 0.37, p<0.001).

\section{Factors Associated with PCPs' Thinking that Their Patients had Misused Opioids}

In a multivariable regression model after adjusting for patients' age, sex, race, and history of illicit substance use in the past year, PCPs were more likely to think that younger patients (Adjusted Odds Ratio (AOR) 0.89, 95\% CI 0.84-0.97), African American patients (AOR 2.53, 95\% CI 1.05-6.07), and those who had used illicit substances in the past year (AOR 3.33, 95\% CI 1.35-8.20) had misused opioids (Table 5). Younger (AOR 0.94, 95\% CI 0.86-1.02) and African American (AOR $0.71,95 \%$ CI 0.25-1.97) patients were not more likely to report misusing opioids; but those who had used illicit substances in the past year had three-fold higher odds of misuse than those who had not (AOR 3.01, 95\% CI 1.04-8.76).

\section{DISCUSSION}

We found that PCPs judgments of opioid analgesic misuse were discordant with patients' ACASI self-reports. PCPs were more likely to overestimate misuse in younger and African American patients. PCPs determinations of misuse were more accurate among patients with histories of illicit substance use. To our knowledge, this is the first study that compares PCPs' estimates of prescription opioid misuse with patients' ACASI self-reports. Our study highlights the challenges of determining and monitoring opioid misuse.

We selected patients who were indigent and living in an urban poor neighborhood to reflect a group of patients thought to be at increased risk of misuse. Despite this, PCPs were more likely to think that African American patients had misused opioid analgesics, even though they were no more likely to report misuse. Patients' race was shown to be associated with clinicians' perceptions of patients' likelihood of risk behaviors ${ }^{16}$. White patients are more likely to be prescribed opioid analgesics for the treatment of chronic pain than nonwhites; ${ }^{15}$ though, no evidence points to a higher risk of misuse by non-whites ${ }^{7,8}$. Studies suggest that providers invoke racially based stereotypes when faced with clinical ambiguity or complex medical decisions ${ }^{39}$. In the absence of adequate training or objective measures to determine misuse, PCPs may have unknowingly relied on racially based clinical stereotypes when making these assessments ${ }^{16}$. PCPs' lack of knowledge and training on determining opioid misuse may increase the probability of use of these stereotypes to determine patient behaviors.

Table 5. Factors Associated with Primary Care Providers' Thinking that Their Patients had Misused Opioid Analgesics in the Past Year $(\mathrm{N}=105)$

\begin{tabular}{lll}
\hline \hline Factors & $\begin{array}{l}\text { Unadjusted } \\
\text { Odds Ratio 95\% Cl }\end{array}$ & $\begin{array}{l}\text { Adjusted Odds } \\
\text { Ratio 95\% Cl }\end{array}$ \\
\hline Age & $0.92(0.86-0.98)^{*}$ & $0.89(0.84-0.97)^{\dagger}$ \\
Sex (ref. Women) & $1.34(0.61-2.96)$ & $1.02(0.42-2.43)$ \\
$\begin{array}{l}\text { African American } \\
\text { (ref. non-African American) }\end{array}$ & $1.78(0.82-3.85)$ & $2.53(1.05-6.07)^{\ddagger}$ \\
$\begin{array}{l}\text { History of substance use } \\
\text { in the past year }\end{array}$ & $2.10(0.96-4.61)$ & $3.33(1.35-8.20)^{\S}$ \\
\end{tabular}

\footnotetext{
$p<0.01$

$p<0.004$

\# $p<0.04$

§ $p<0.009$
} 
PCPs were more likely to think that younger patients had a higher risk of misuse. Younger age was found to be a consistent predictor of opioid misuse among the general patient population ${ }^{7,8,37}$. However, younger age was not associated with misuse in our study. Uniformly applying established predictors without contextualizing to the target patient population might result in erroneous conclusions.

PCPs' identification of illicit substance use was better than that of prescription opioid analgesic misuse. Tools such as urine toxicology screens are easier to interpret for presence of illicit substances than for assessing prescription opioid misuse. Illicit substance use in the past year was associated with patients' self-reports of opioid misuse. These findings are supported by prior studies that showed that illicit substance use was one of the most reliable predictors of future prescription opioid misuse in clinic-based samples ${ }^{7,9}$.

Given the difficulty in making these assessments, several risk stratification tools have been developed to help providers identify patients at risk for misuse, though none of these tools have been validated in high-risk patients seen in primary care clinics $^{17,18,21-23}$. In the absence of a single, gold-standard test for determining opioid analgesic misuse, PCPs need to be conscious of their preconceptions and substantiate their clinical judgments of misuse with all available tools. Studies that examine the predictive validity as well as applicability of these tools to primary care providers caring for high-risk patients are needed.

The high-risk patients in our study were representative of those who are disproportionately affected by chronic pain and co-occurring substance use disorders ${ }^{4,40}$ and are routinely treated in primary care practices that lack the resources of specialty pain clinics. Therefore, identifying better strategies to monitor opioid misuse and providing additional resources for patients with co-occurring substance use disorders is important given rising rates of opioid misuse and the serious consequences of overdose ${ }^{41,42}$.

We note several limitations. We relied on patients' self report as the 'gold standard', which may have underestimated the prevalence of opioid analgesic misuse and illicit substance use. This may have lead to misclassification bias. We tried to minimize underreporting by using ACASI technology, which reduces barriers in reporting sensitive information ${ }^{30,43}$. While self-reports may have lead to underreporting, other methods such as urine toxicology screens are similarly imperfect. A recent systematic review concluded that there was inadequate evidence to support using urine toxicology tests to determine opioid misuse, and highlighted the difficulty of using 'objective' data for measuring misuse ${ }^{24,25}$. Despite our overall good response rate for PCPs, we did not have information on nonresponders, thus introducing a potential for selection bias. Our patients were poor, HIV-infected, from one urban area, and had high rates of chronic pain and illicit substance use, limiting the generalizability of our findings. However, these findings may be applicable to other urban, poor, non-HIV infected patient populations with a high burden of chronic pain, depression, and substance use disorders ${ }^{44-46}$.

Our study had several strengths. Patients were recruited systematically from high-risk communities, and from these, we selected those who were prescribed opioid analgesics. We minimized recall bias by obtaining self-reports in the past 90 days instead of the past year. Patients reported misuse using ACASI at a community-based research site separate from clinical settings.
We recruited PCPs from diverse clinical settings including general and HIV specific community health clinics, private practices and university-affiliated medical practices.

We found that PCPs' assessments of opioid misuse were discordant with patients' self-reports and appeared to factor patients' age and race incorrectly. As use and misuse of these medications continue to rise, PCPs will need more reliable means of determining misuse. Increasing awareness among PCPs about the harmful effects of racially based heuristic shortcuts on clinical assessments of misuse and providing education on contextualizing risk and incorporating individual patient experiences may improve the accuracy of estimates of misuse.

Contributors: The authors would like to thank Jennifer Mattson, $B A$ for her invaluable assistance in preparing this manuscript and Jane Liebschutz, MD for her thoughtful comments on the manuscript. We would like to thank the research assistants for conducting the patient interviews. We would also like to thank all the patients and their PCPs for their contribution to this study.

Funders: This study was funded by the Pain Study grant from the National Institute on Drug Abuse R01DA022550, and the REACH study grant from the National Institute of Mental Health R01MH54907. Additional funding includes the Department of Health and Human Services - Health Resources and Services Administration, Primary Care Research Fellowship grant D55HP05165 (Dr. Vijayaraghavan). The Tenderloin Center for Clinical Research was supported by the University of California, San Francisco (UCSF), Clinical and Translational Institute grant, NIH/NCRR UCSF-CTSI UL1 RRO24131. The funders had no role in the design or conduct of the study or the preparation of the manuscript.

Previous Presentation: Results from this study were presented at the Annual Meeting of the Society of General Internal Medicine Conference; April 29, 2010; Minneapolis, Minnesota.

Conflict of Interest: None disclosed.

Open Access: This article is distributed under the terms of the Creative Commons Attribution Noncommercial License which permits any noncommercial use, distribution, and reproduction in any medium, provided the original author(s) and source are credited.

Corresponding Author: Margot B. Kushel, MD; Division of General Internal Medicine/San Francisco General Hospital, University of California, San Francisco, Box 1364, San Francisco, CA 941431364, USA (e-mail: mkushel@medsfgh.ucsf.edu).

\section{REFERENCES}

1. Gilson AM, Ryan KM, Joranson DE, Dahl JL. A reassessment of trends in the medical use and abuse of opioid analgesics and implications for diversion control: 1997-2002. J Pain Symptom Manage. 2004;28(2):17688.

2. Edlund MJ, Martin BC, Devries A, Fan MY, Braden JB, Sullivan MD. Trends in use of opioids for chronic noncancer pain among individuals with mental health and substance use disorders: the TROUP study. Clin J Pain. 2010;26(1):1-8.

3. Manchikanti L, Pampati V, Damron KS, Fellows B, Barnhill RC Beyer CD. Prevalence of opioid abuse in interventional pain medicine practice settings: a randomized clinical evaluation. Pain Physician. 2001;4(4):358-65.

4. Manchikanti L, Cash KA, Damron KS, Manchukonda R, Pampati V, McManus CD. Controlled substance abuse and illicit drug use in chronic 
pain patients: an evaluation of multiple variables. Pain Physician. 2006;9(3):215-25.

5. Reid MC, Engles-Horton LL, Weber MB, Kerns RD, Rogers EL, O'Connor PG. Use of opioid medications for chronic noncancer pain syndromes in primary care. J Gen Intern Med. 2002;17(3):173-9.

6. Chelminski PR, Ives TJ, Felix KM, et al. A primary care, multidisciplinary disease management program for opioid-treated patients with chronic non-cancer pain and a high burden of psychiatric comorbidity. BMC Health Serv Res. 2005;5(1):3.

7. Ives TJ, Chelminski PR, Hammett-Stabler CA, et al. Predictors of opioid misuse in patients with chronic pain: a prospective cohort study. BMC Health Serv Res. 2006;6:46.

8. Edlund MJ, Steffick D, Hudson T, Harris KM, Sullivan M. Risk factors for clinically recognized opioid abuse and dependence among veterans using opioids for chronic non-cancer pain. Pain. 2007;129(3):355-62.

9. Michna E, Ross EL, Hynes WL, et al. Predicting aberrant drug behavior in patients treated for chronic pain: importance of abuse history. J Pain Symptom Manage. 2004;28(3):250-8.

10. Breitbart W, Rosenfeld BD, Passik SD, McDonald MV, Thaler H, Portenoy RK. The undertreatment of pain in ambulatory AIDS patients. Pain. 1996;65(2-3):243-9.

11. Breitbart W, Passik S, McDonald Mv, et al. Patient-related barriers to pain management in ambulatory AIDS patients. Pain. 1998;76(1-2):916.

12. Hewitt DJ, McDonald M, Portenoy RK, Rosenfeld B, Passik S, Breitbart W. Pain syndromes and etiologies in ambulatory AIDS patients. Pain. 1997;70(2-3):117-23.

13. Lebovits AH, Smith G, Maignan M, Lefkowitz $\mathbf{M}$. Pain in hospitalized patients with AIDS: analgesic and psychotropic medications. Clin J Pain. 1994; 10(2): 156-61.

14. Passik SD, Kirsh KL, Donaghy KB, Portenoy RK. Pain and aberrant drug-related behaviors in medically ill patients with and without histories of substance abuse. Clin J Pain. 2006;22(2):173-81.

15. Burgess DJ, Crowley-Matoka M, Phelan S, et al. Patient race and physicians' decisions to prescribe opioids for chronic low back pain. Soc Sci Med. 2008;67(11):1852-60.

16. van Ryn M, Burke J. The effect of patient race and socio-economic status on physicians' perceptions of patients. Soc Sci Med. 2000;50 (6):813-28.

17. Butler SF, Budman SH, Fernandez K, Jamison RN. Validation of a screener and opioid assessment measure for patients with chronic pain. Pain. 2004;112(1-2):65-75.

18. Webster LR, Webster RM. Predicting aberrant behaviors in opioidtreated patients: preliminary validation of the Opioid Risk Tool. Pain Med. 2005;6(6):432-42.

19. Chou R, Fanciullo GJ, Fine PG, Miaskowski C, Passik SD, Portenoy RK. Opioids for chronic noncancer pain: prediction and identification of aberrant drug-related behaviors: a review of the evidence for an American Pain Society and American Academy of Pain Medicine clinical practice guideline. J Pain. 2009;10(2):131-46.

20. Compton PA, Wu SM, Schieffer B, Pham Q, Naliboff BD. Introduction of a self-report version of the prescription drug use questionnaire and relationship to medication agreement noncompliance. J Pain Symptom Manage. 2008;36(4):383-95.

21. Compton P, Darakjian J, Miotto $\mathbf{K}$. Screening for addiction in patients with chronic pain and "problematic" substance use: evaluation of a pilot assessment tool. J Pain Symptom Manage. 1998;16(6):355-63.

22. Butler SF, Budman SH, Fernandez KC, et al. Development and validation of the current opioid misuse measure. Pain. 2007;130(12):144-56.

23. Turk DC, Swanson KS, Gatchel RJ. Predicting opioid misuse by chronic pain patients: a systematic review and literature synthesis. Clin J Pain. 2008;24(6):497-508.

24. Pergolizzi J, Pappagallo M, Stauffer J, et al. The role of urine drug testing for patients on opioid therapy. Pain Pract. 2010. [Epub ahead of print]
25. Starrels JL, Becker WC, Alford DP, Kapoor A, Williams AR, Turner BJ. Systematic review: treatment agreements and urine drug testing to reduce opioid misuse in patients with chronic pain. Ann Intern Med. 2010;152(11):712-20.

26. Reisfield GM, Bertholf R, Barkin RL, Webb F, Wilson G. Urine drug test interpretation: what do physicians know? J Opioid Manag. 2007;3 (2):80-6.

27. Wasan AD, Butler SF, Budman SH, Benoit C, Fernandez K, Jamison RN. Psychiatric history and psychologic adjustment as risk factors for aberrant drug-related behavior among patients with chronic pain. Clin J Pain. 2007;23(4):307-15.

28. Robertson MJ, Clark RA, Charlebois ED, et al. HIV seroprevalence among homeless and marginally housed adults in San Francisco. Am J Public Health. 2004;94(7): 1207-17.

29. Robins LN, Helzer JE, Croughan J, Ratcliff KS. National Institute of Mental Health Diagnostic Interview Schedule. Its history, characteristics, and validity. Arch Gen Psychiatry. 1981;38(4):381-9.

30. Riley ED, Chaisson RE, Robnett TJ, Vertefeuille J, Strathdee SA, Vlahov D. Use of audio computer-assisted self-interviews to assess tuberculosis-related risk behaviors. Am J Respir Crit Care Med. 2001;164(1):82-5.

31. Dillman DA. Mail and Telephone Surveys: The Total Design Method. New York: Wiley; 1978.

32. Beck A, Steer R, Brown G. Manual for Beck Depression Inventory-II. San Antonio: Psychological Corporation; 1996.

33. Storch EA, Roberti JW, Roth DA. Factor structure, concurrent validity, and internal consistency of the Beck Depression Inventory-Second Edition in a sample of college students. Depress Anxiety. 2004;19(3):187-9.

34. Keller S, Bann CM, Dodd SL, Schein J, Mendoza TR, Cleeland CS. Validity of the brief pain inventory for use in documenting the outcomes of patients with noncancer pain. Clin J Pain. 2004;20(5):309-18.

35. Serlin RC, Mendoza TR, Nakamura Y, Edwards KR, Cleeland CS. When is cancer pain mild, moderate or severe? Grading pain severity by its interference with function. Pain. 1995;61(2):277-84.

36. Arvanitis ML, Satonik RC. Transdermal fentanyl abuse and misuse. Am J Emerg Med. 2002;20(1):58-9.

37. Chabal C, Erjavec MK, Jacobson L, Mariano A, Chaney E. Prescription opiate abuse in chronic pain patients: clinical criteria, incidence, and predictors. Clin J Pain. 1997;13(2):150-5.

38. Dunbar SA, Katz NP. Chronic opioid therapy for nonmalignant pain in patients with a history of substance abuse: report of 20 cases. J Pain Symptom Manage. 1996;11(3): 163-71.

39. Van Ryn M. Research on the provider contribution to race/ethnicity disparities in medical care. Med Care. 2002;40(1 Suppl):I140-51.

40. Potter JS, Prather K, Weiss RD. Physical pain and associated clinical characteristics in treatment-seeking patients in four substance use disorder treatment modalities. Am J Addict. 2008;17(2):121-5.

41. Dunn KM, Saunders KW, Rutter CM, et al. Opioid prescriptions for chronic pain and overdose: a cohort study. Ann Intern Med. 2010;152 (2):85-92.

42. Hall AJ, Logan JE, Toblin RL, et al. Patterns of abuse among unintentional pharmaceutical overdose fatalities. JAMA. 2008;300 (22):2613-20.

43. Metzger DS, Koblin B, Turner C, et al. Randomized controlled trial of audio computer-assisted self-interviewing: utility and acceptability in longitudinal studies. HIVNET Vaccine Preparedness Study Protocol Team. Am J Epidemiol. 2000;152(2):99-106.

44. Yancy WS Jr, Macpherson DS, Hanusa BH, et al. Patient satisfaction in resident and attending ambulatory care clinics. J Gen Intern Med. 2001;16(11):755-62.

45. Fiebach NH, Wong JG. Taking care of patients in resident clinics: where do we stand? J Gen Intern Med. 2001;16(11):787-9.

46. Brook RH, Fink A, Kosecoff $\mathbf{J}$, et al. Educating physicians and treating patients in the ambulatory setting. Where are we going and how will we know when we arrive? Ann Intern Med. 1987;107(3):392-8. 